\title{
Foucault e a governamentalidade democrática: a questão da precarização da educação inclusiva
}

\author{
Foucault and the democratic governmentality: the issue of the \\ preacarioness of the inclusive education
}

\author{
Alexandre Filordi de Carvalho; Silvio D. de Oliveira Gallo \\ Universidade Federal de São Paulo; Universidade Estadual de Campinas
}

\section{RESUMO:}

Neste texto investigam-se os processos de inclusão levados a cabo na política educacional brasileira entre 1985 e 2016, bem como sua precarização nos dias de hoje. Para compreender tais processos, usa-se a biopolítica de Michel Foucault e seu operador conceitual governamentalidade, colocando-se a hipótese de que teríamos nas últimas três décadas o desenvolvimento no Brasil de uma governamentalidade democrática, que operou uma lógica inclusiva para o governo das diferenças. No atual momento político, em que aquela estratégia já não opera, vivemos um neoliberalismo exacerbado, que precariza os corpos diferentes, que já não cabem na lógica do capital e de sua produção. Em tal contexto, a defesa da escola pública democrática e republicana ganha especial importância e atualidade.

Palavras-chave: educação; inclusão; biopolítica; governamentalidade

\begin{abstract}
:
This paper investigates the inclusion processes carried out in Brazilian educational policy between 1985 and 2016, as well as their precariousness today. To understand these processes, Michel Foucault's biopolitics and its conceptual operator governmentality are used, sustaining the hypothesis that we would have in the last three decades the development in Brazil of a democratic governmentality, which operated an inclusive logic for the government of differences. In the current political moment, when that strategy no longer operates, we are experiencing an exacerbated neoliberalism, which makes different bodies precarious, which no longer fit the logic of capital and its production. In such a context, the defense of the democratic and republican public school gains special importance and relevance.
\end{abstract}

Key-words: education; inclusion; biopolitics; governmentality

DOI: 10.12957/mnemosine.2020.52688

\section{Problematizações iniciais}

É precisamente durante essas rupturas que a gente consegue se livrar da postura de "governado" e reencontrar o enfrentamento, a estratégia e a abertura dos possiveis [...] destruindo a relação de poder de que tanto o patrão quanto o trabalhador são a expressão.

(LAZZARATO, 2019: 98-99. Grifos originais) 
Após o rompimento institucional da democracia brasileira, tendo como marcador histórico o impeachment produzindo contra a presidenta Dilma Rousseff, o "ódio instituído na política brasileira" (GALLEGO, 2018) desde 2016, emergiu uma enunciação visando a combater as experiências e as teorias educativas voltadas para as diferenças e as políticas afirmativas de inclusão social.

Junto a isso, tomamos conhecimento da vertiginosa desidratação dos recursos econômicos destinados à educação, enquanto o gerencialismo neoliberal passou a enfatizar a perspectiva tecnopolítica de "gastos" e de "custos" para a educação, no lugar de compreender o capital aplicado à educação como investimento nas condições de transformação humana. O documento Aspectos Fiscais da Educação no Brasil, emitido pelo Tesouro Nacional em 2018, oferece farta prova de tal perspectiva.

Ao assumir o Governo Federal em janeiro de 2019, a administração, imediatamente, suprimiu a Secretaria de Educação Continuada, Alfabetização, Diversidade e Inclusão - SECADI. No dia 9 de outubro do mesmo ano, o Governo Federal vetou o projeto de lei $n^{\circ}$. 3.688/2000 que dispunha sobre a prestação de serviços de psicologia e de serviço social nas redes públicas de educação básica. Tal projeto definia:

Art. $1^{o}$. As redes públicas de educação básica contarão com serviços de psicologia e de serviço social para atender às necessidades e prioridades definidas pelas políticas de educação, por meio de multiprofissionais.

$\S 1^{o}$. As equipes multiprofissionais deverão desenvolver ações para a melhoria da qualidade do processo de ensino-aprendizagem, com a participação da comunidade escolar, atuando na mediação das relações sociais e institucionais.

$\S 2^{\circ}$. O trabalho da equipe multiprofissional deverá considerar o projeto políticopedagógico das redes públicas de educação básica e dos seus estabelecimentos de ensino. (CÂMARA DOS DEPUTADOS: 2000)

O argumento para o veto: ausência da respectiva fonte de custeio e a ausência dos respectivos impactos orçamentários e financeiros. Ironicamente, na mesma semana, o Governo Federal anunciava autorização prévia da construção do Museu da Bíblia em Brasília, mas sem mencionar a respectiva fonte de custeio e os impactos orçamentários e financeiros, embora estimada em torno de 100 milhões de reais. 
Como compreender o impacto no campo educativo dessas radicais transformações pelas quais tem passado o governo brasileiro nestes últimos anos, desde 2017, com a ascensão de Michel Temer e a posterior eleição de Jair Messias Bolsonaro?

Nesse artigo tentaremos contribuir para essa tarefa complexa, com um recorte bem específico: a noção de biopolítica pensada por Michel Foucault. Tomaremos o Brasil como um "laboratório biopolítico", em que ações em torno de um "governo da vida" são postas em prática, testadas, aperfeiçoadas, sempre a partir de uma lógica de governo. Mostraremos como, em um primeiro momento, estabeleceu-se entre nós uma lógica governamental de governo das diferenças, devidamente incluídas na ordem de uma política democrática, para depois se passar a uma precarização de tais estratégias.

\section{A produção de uma "governamentalidade democrática" e o governo das diferenças}

Comecemos com um esclarecimento em torno do operador conceitual governamentalidade, introduzido por Foucault. O filósofo comentou (FOUCAULT, 2014a: 69-72) que produziu em sua obra dois deslocamentos teóricos importantes. O primeiro foi deixar de lado as análises através da ideologia, para enveredar-se pela análise das relações saber-poder; o segundo deslocamento consistiu em introduzir a noção de que os seres humanos são governados pela verdade. Trata-se de uma mudança de foco com relação às análises centradas nas relações saber-poder, uma vez que o poder é substituído por algo mais abrangente, o governo, enquanto o saber é restringido à noção de verdade.

Ao colocar foco nas relações de poder para compreendê-lo como ação, Foucault chegou às "artes de governar", exploradas e aprofundadas por Senellart (2006), isto é, à forma de atuação dos Estados modernos em que passaram a agir através de uma biopolítica, um governo sobre os viventes, controlando as ações destes através de políticas públicas que estão orientadas para um controle populacional. É desta análise que derivaria o conceito de governamentalidade. Esta não se resume a uma condução das condutas dos indivíduos, mas opera também na sua constituição psíquica, operando processos de subjetivação (COMBES, 2011; FOUCAULT, 2013, 2014a, 2014b).

A governamentalização dos Estados ocidentais modernos foi, segundo Foucault, a culminação de um processo histórico que teve início com os Estados soberanos medievais e assumiria sua feição atual a partir do século XVIII. Para ele, este processo de governamentalização do Estado é mais importante e diz mais sobre nossa configuração social do que um processo de estatização da sociedade (FOUCAULT, 2008a:144-145), 
visto que foi ele que oportunizou a emergência dos neoliberalismos, conforme analisa em outra obra (FOUCAULT, 2008b). Em sua análise,

vivemos na era da "governamentalidade", aquela que foi descoberta no século XVIII. Governamentalização do Estado que é um fenômeno particularmente tortuoso, pois, embora efetivamente os problemas da governamentalidade, as técnicas de governo tenham se tornado de fato o único intuito político e o único espaço real da luta e dos embates políticos, essa governamentalização do Estado foi, apesar de tudo, o fenômeno que permitiu ao Estado sobreviver. E é possivel que, se o Estado existe tal como ele existe agora, seja precisamente graças a essa governamentalidade que é ao mesmo tempo exterior e interior ao Estado, já que são as táticas do governo que, a cada instante, permitem definir o que deve ser do âmbito do Estado e o que não deve, o que é público e o que é privado, o que é estatal e o que é não-estatal. Portanto, se quiserem, o Estado em sua sobrevivência e o Estado em seus limites só devem ser compreendidos a partir das táticas gerais da governamentalidade. (FOUCAULT, 2008a: 145).

O processo de governamentalização do Estado foi, assim, o responsável pela configuração do mundo contemporâneo. De modo esquemático, Foucault aponta que no período medieval tivemos um Estado de justiça, com uma territorialidade feudal e que operava no âmbito da lei, o que significa que o exercício do poder estatal era, sobretudo, legislativo; tal conformação foi substituída por um Estado administrativo, com uma territorialidade marcada pelas fronteiras, consolidando-se ao longo dos séculos XV e XVI, que operava por regulamentação e disciplinarização (marcado pelo exercício do poder disciplinar); por fim, vimos emergir, a partir do século XVIII, um Estado de governo, caracterizado pela população que ocupa seu território, operando através da condução das condutas desta população, com um poder caracterizado como um exercício da garantia da vida da população.

Foucault desenvolveu diversas explorações conceituais em torno das artes de governar, da governamentalidade, e não é nosso objetivo aqui passá-las em revista. De modo breve, diz-se-ía que governar significa conduzir condutas. Isto é, as pessoas agem, nos mais variados contextos, elas se conduzem; governar não é impor uma conduta ou conjunto de condutas, mas orientar, conduzir as condutas das pessoas. $\mathrm{Na}$ análise de Foucault, isso se dá nos mais variados âmbitos da vida humana: indivíduos conduzem-se a si mesmos (governo de si, no âmbito de uma moralidade); pais conduzem as condutas dos filhos; professores conduzem as condutas dos alunos (governo do outro, no âmbito de uma pedagogia); pais e mães de família conduzem as condutas de seus membros, de modo a garantir o bem estar de todos (governo familiar, no âmbito de uma economia), e assim por diante. São práticas dessa natureza que levarão a um processo de se pensar e praticar o Estado como uma arte de governar, como uma prática de condução da conduta 
de seus cidadãos. É essa "continuidade ascendente" que produz o Estado governamentalizado, ainda que possamos também identificar uma "continuidade descendente", que parte da vida política do Estado e chega à vida cotidiana dos indivíduos.

A governamentalidade caracteriza, pois, uma certa forma de ação do Estado no exercício do poder sobre os indivíduos, consistindo, especialmente, na construção de formas de conduzir, a partir de seu âmbito, as condutas dos indivíduos, seja em sociedade, seja nas particularidades da vida de cada um. O Estado, porém, não se dirige a cada um dos indivíduos, mas a seu agrupamento numa população. Através do conjunto populacional, o Estado chega a cada indivíduo, atingindo, segundo Foucault (2003), omnes et singulatim. ${ }^{1}$ As estratégias de governo pelo Estado só puderam se desenhar a partir da emergência de uma biopolítica, de um poder que se exerce massivamente sobre a vida das populações, visando a controlar sua progressão. Como exemplos, podemos citar os sistemas de controle de natalidade, os sistemas de previdência social, as políticas públicas nos campos da saúde e da educação, e mais atualmente, toda forma de controle e filtragrem sociais em torno do COVID-19, compreendendo imposição de circulação humana, regras de higiene e de contato social, priorização na hospitalização, fechamentos de escolas, e sucessivamente.

Segundo Foucault, o governo articula aquilo que Habermas denominou "técnicas de dominação"2 com o que ele próprio denominou "técnicas de si":

O ponto de contato, que produz a articulação entre a forma pela qual os indivíduos são dirigidos por outrem e forma pela qual eles se dirigem a si mesmos é aquilo que, penso, podemos denominar "governo". Governar as pessoas, no sentido largo da palavra, não é uma maneira de forçá-las a fazer aquilo que quer aquele que governa; há sempre um equilíbrio instável, com complementaridade e conflitos, entre as técnicas que asseguram a coerção e os processos pelos quais o si é construído e modificado por si mesmo. (FOUCAULT, 2013: 38-39)

Destacamos o ponto acima citado para enfatizar que, na analítica foucaultiana, governar pressupõe liberdade. Governar uma população não é tolher-lhe a liberdade, dominá-la, impedindo suas ações; ao contrário, governar uma população implica em conhecer suas condutas e esforçar-se por conduzir essas condutas, não impondo condutas totalmente alheias. Por essa razão, dentre outras, pode-se dizer que os Estados modernos governamentalizados são, ao mesmo tempo, criadores e resultantes do liberalismo clássico, da mesma forma que forneceram a base para a emergência dos neoliberalismos. 
A análise de Foucault foi realizada, evidentemente, a partir do contexto europeu, com centralidade para o Estado francês. Quando pensamos em governamentalização do Estado no Brasil, precisamos estar atentos às particularidades de nossa história. Não podemos falar em Estado brasileiro durante o período colonial e o Estado português, à época, operava, sobretudo, no modelo da justiça, da soberania. Com a independência, no início do século XIX, institui-se um Estado brasileiro. Nessa época, na Europa, já víamos a consolidação dos Estados governamentalizados; aqui, foi necessário construir um Estado e pode-se dizer que os 67 anos de um Estado imperial mesclaram características dos três tipos propostos por Foucault, embora claramente não tenha se consolidado um Estado governamentalizado. Este ganhou força apenas no final do século XIX, com a instituição de um Estado republicano. ${ }^{3}$

À diferença da governamentalização dos Estados europeus, pensamos que o processo brasileiro passou por diferentes fases, que podem ser identificadas e analisadas; aqui, ficaremos restritos às últimas décadas, em um período demarcado entre 1985, com o início de redemocratização depois de 21 anos de ditadura civil-militar, e 2016, com o impeachment de Dilma Rousseff. Defendemos a hipótese de que neste período constituise no país o que denominamos uma "governamentalidade democrática". 4

Por que essa denominação? Ora, porque neste período histórico tivemos um processo de redemocratização no país, sendo a afirmação da cidadania e da participação política nas decisões a lógica dominante na forma pela qual fomos governados. Após duas décadas de ditadura, estando o povo alijado da efetiva participação, urgia fazer com que todos e cada um fossem subjetivados como cidadãos, como sujeitos de direitos políticos e sociais, partícipes nas tomadas de decisão sobre os rumos da sociedade brasileira. Governamentalidade democrática: uma prática de governo dos cidadãos, na qual eles são livres para tomar suas decisões e chamados a participar da sociedade nas mais variadas esferas e instâncias.

A Constituição Federal de 1988, saudada por Ulysses Guimarães, Presidente da Assembleia Nacional Constituinte, como "a Constituição cidadã", teve na cidadania e na afirmação dos direitos dos cidadãos um de seus pilares centrais. A afirmação da cidadania presidiria também a Lei n 9394/96, Lei de Diretrizes e Bases da Educação Nacional, que define em seu artigo segundo: “A educação, dever da família e do Estado, inspirada nos princípios de liberdade e nos ideais de solidariedade humana, tem por finalidade o pleno desenvolvimento do educando, seu preparo para o exercício da cidadania e sua 
qualificação para o trabalho" (grifos nossos). São duas as finalidades da educação brasileira desde aquela data: qualificar para o exercício profissional, de modo que o educando possa se inserir no mundo do trabalho e preparar para o exercício da cidadania, de modo que sua participação social e política estejam asseguradas. Se acompanharmos a extensa produção de políticas públicas no campo da educação brasileira desde então, veremos que nenhuma delas destoa da lógica a afirmação da cidadania, da função de subjetivar os estudantes como cidadãos sujeitos de direitos. ${ }^{5}$

Aqui nos detemos no âmbito de uma educação das diferenças e para as diferenças. $\mathrm{Na}$ lógica de uma educação democrática e republicana, necessariamente para todos, o princípio da inclusão é fundamental. Aqueles que eventualmente fiquem de fora, não fazendo parte do conjunto dos cidadãos, não podem ser governados; fora da cidadania não há governo democrático possível. A perspectiva de uma educação inclusiva, portanto, é uma aliada direta e necessária de uma educação democrática.

No âmbito de uma governamentalidade democrática que opera pelo governo dos cidadãos, todos devem estar incluídos nesta categoria e ter acesso à escola republicana, sem distinções de sexo, etnia, pessoas como dificuldades motoras, com dificuldades de aprendizagem e assim por diante. No ano de 2013 foi publicado pela Secretaria de Educação Continuada, Alfabetização, Diversidade e Inclusão do Ministério da Educação um documento norteador, as Diretrizes Curriculares Nacionais para a Educação Básica: Diversidade e Inclusão. Este documento tem o mérito de sistematizar e sintetizar um conjunto extensivo de políticas públicas inclusivas produzidas ao longo dos anos por aquele órgão de governo.

Destacamos uma longa passagem da introdução destas Diretrizes, na qual ficam evidentes os princípios da lógica da inclusão educativa no âmbito de uma governamentalidade democrática:

Um dos desafios posto pela contemporaneidade às políticas educacionais é o de garantir, contextualizadamente, o direito humano universal, social inalienável à educação. $O$ direito universal deve ser analisado isoladamente em estreita relação com outros direitos, especialmente, dos direitos civis e políticos e dos direitos de caráter subjetivo, sobre os quais a educação incide decisivamente.

Nessa perspectiva, torna-se inadiável trazer para o debate os princípios e as práticas de um processo de inclusão social, que garanta o acesso à educação e considere a diversidade humana, social, cultural, econômica dos grupos historicamente excluídos. Trata-se das questões de classe, gênero, raça, etnia, geração, constituídas por categorias que se entrelaçam na vida social, mulheres, afrodescendentes, indígenas, pessoas com deficiência, populações do campo, de diferentes orientações sexuais, sujeitos albergados, em situação de rua, em 
privação de liberdade, de todos que compõem a diversidade que é a sociedade brasileira e que começam a ser contemplados pelas políticas públicas.

Para que se conquiste a inclusão social, a educação escolar deve fundamentarse na ética e nos valores da liberdade, na justiça social, na pluralidade, na solidariedade e na sustentabilidade, cuja finalidade é o pleno desenvolvimento de seus sujeitos, nas dimensões individual e social de cidadãos conscientes de seus direitos e deveres, compromissados com a transformação social. (CRAVERIO; MEDEIROS, 2013: 7)

Neste importante documento, cujo mérito central é o de articular os múltiplos e diferenciados campos dos distintos grupos sociais que precisam estar presentes numa lógica inclusiva para que a educação seja garantida pelo Estado como direito de todos e de cada um dos cidadãos, evidencia-se uma confusão entre diferença e diversidade. Não entraremos aqui no debate conceitual implicado nessa afirmação, já desenvolvido em outro lugar (GALLO, 2017), mas interessa-nos ao menos salientar que enquanto a diversidade pode ser pensada e abarcada numa lógica da universalidade (o "direito universal" indicado no documento), a diferença só pode ser pensada numa lógica do múltiplo, que escapa a toda e qualquer universalização.

Nos limites deste texto, o que queremos demarcar é que, entre 1985 e 2016, tendo se desenvolvido no país uma governamentalidade democrática que presidiu a produção biopolítica de políticas públicas no campo da educação centradas na formação para a cidadania e na inclusão, houve um intenso processo de afirmação das diferenças, sob a lógica do governo. Em outros termos, as diferenças foram afirmadas, de modo a serem acolhidas no processo democrático da participação cidadã, tendo seus direitos consolidados. Na lógica da governamentalidade, incluir as diferenças implica em governá-las; a inclusão se faz justamente porque aqueles que ficarem de fora não poderão ser governados. O que tivemos durante as três décadas de governamentalidade democrática foi, então, uma ação de governo das diferenças e dos diferentes segundo o princípio da cidadania e dos direitos. Não podemos deixar de reafirmar, porém, que nesta analítica inspirada em Foucault, incluir e governar não implicam em tolher liberdades, mas em reconhecê-las, operando o governo de todos e de cada um de forma a conduzir as condutas em um contexto democrático e participativo.

A esta lógica política poderíamos contrapor outras, por exemplo, lógicas políticas em que os diferentes não se deixam governar. ${ }^{6}$ Porém, nos limites impostos por este texto não entraremos em tal contexto. Interessa-nos mais enveredar pelo contemporâneo, por aquilo que se tem produzido depois do processo de impeachment presidencial de 2016, 
que colocou fim a uma ordem política marcada pela governamentalidade democrática e iniciou outra ordem política, sobre a qual podemos somente, por ora, tatear. É claro que o governo Temer, ao longo de 2017 e 2018, iniciou o desmonte das políticas afirmativas e inclusivas produzidas e consolidadas ao longo das três décadas anteriores e que o governo iniciado em 2019 acelerou ao limite este desmonte, levando a uma intensa precarização das diferenças e dos diferentes. Disso trataremos em seguida.

\section{Neoliberalismo e precarização dos diferentes: o sucateamento da educação pública}

As pesquisas de Guy Standing (2017) em O precariado - a nova classe perigosa; de Hosang e Lowndes (2019) em Trabalhadores, Parasitas, Patriotas - raça e a política de precariedade da extrema direita, sem mencionar o impactante artigo de Jodi Melamed (2006) O espírito do neoliberalismo: do liberalismo racial ao multiculturalismo racial, despontam dados vertiginosos. Na ponta mais frágil da cadeia meritocrática que assola o globo, migrantes, afrodescendentes, mulheres, trabalhadores asiáticos, minorias sexuais, étnicas, econômicas, religiosas, além de crianças e de adolescentes têm sofrido o impacto exploratório e desumanizador da tecnologia política neoliberal de precarização.

Desse ponto de vista, o tecnicismo e a mercadorização avassaladores que vêm contaminando a política da educação pública brasileira convergem para o sucateamento da própria educação pública. É como se houvesse uma espécie de parasita neoliberal nas intenções educacionais, já que o objetivo da educação também passa pelo retorno financeiro sobre o gasto, como dá testemunho o Future-se. Erodir toda e qualquer possibilidade de refinamento intelectual, cultural, simbólico na formação humana converge para o condicionamento dos sujeitos em formação com as demandas subjetivas do próprio precariado. Assim, nos argumentos de Standing (2017: 112): "Parte do processo de geração do precariado vem da supersimplificação do sistema educacional". $\mathrm{O}$ assustador, contudo, é que não podemos ignorar que "a experiência de uma existência precarizada de uma geração também transmitirá atitudes e normas de comportamentos para a próxima" (STANDING, 2017: 108).

Em jogo estão: a dissolução da formação humanista, da paciência inerente à longa temporalidade formativa, da substituição da cultura do estudo pelo aprendizado, da escola como investimento na preparação humana para a socialização, a compreensão e a modificação das complexas relações sócio-histórico-naturais. Mas, além disso, encontrase em franca expansão a dissolução da riqueza subjetiva. Para haver a precarização do trabalho, concomitantemente, processou-se a precarização da existência humana como 
gradiente múltiplo, diferente e singular de modos de ser. O padrão meritocrático, nesse caso, é um moedor humano que pasteuriza as dissenções da norma em favor dos mesmos circuitos existenciais.

Aqui passamos a viver em um paradoxo. Pensando o governo das diferenças e aqueles que escapam ao governo, os corpos ingovernáveis são os que se recusam a se submeter a qualquer tipo de precarização existencial, ou que nela não se encaixam por falta de capital humano - que pode ser as próprias normatizações corporais, estéticas, mentais, etc. Mas também ao lhes ser negado o direito de uma educação capaz de potencializar a singularidade de suas existências, ao mesmo tempo, denunciam que a escola está sendo entregue à manipulação da racionalidade rasteira das mesmas demandas de eficiência e de previsibilidade dos corpos. O desmonte da educação inclusiva é precursor do mesmo desmonte da educação pública, pois reduzida à demanda da precariedade, o rolo compressor do Estado pavimenta as condições de formação de um exército de reserva, de um "lumpemprecariado", desde as balizas crônicas da rejeição da ontologia do deficiente ou de qualquer singularidade carente de abordagem não padronizada.

Assim, não seria exagero afirmar que o capitalismo neoliberal, ao sequestrar o Estado, passou a subjugá-lo conforme o fetiche rentista do sistema. Como argumentava Milton Friedman (1955) em O papel do governo na Educação, o único papel do Estado é a garantia de um nível mínimo para que os indivíduos sejam capazes de entender as regras da livre competição e nelas se inserir. Ora, a regra atual, fora da educação elitista, essa, sim, ainda preservando certo refinamento humanista a ser utilizado como distinção ou capital social da elite, tem sido a aprendizagem mínima para o autoinvestimento em si mesmo como ser precariado.

Ora, o precariado se refere a uma figura condizente com a aceleração das fragmentações dos apoios solidários e comunitários, catalisados pela deterioração de relações sociais pautadas na confiança mútua. Conforme propõe Standing (2017: 30), “o precariado não é o nível de salários em dinheiro ou de rendas auferidas em qualquer momento específico, mas a falta de apoio da comunidade em momentos de necessidade, a falta de benefícios assegurados da empresa ou do Estado e a falta de benefícios privados para completar ganhos em dinheiro".

A explosão do precariado consignada pela ênfase na forma do indivíduo unidadeempresa é a consequência neoliberal da destruição de regulações estatais mínimas. 
Regulações que, outrora, já serviram como fiel da balança legal no exercício da garantia de mercado de trabalho, de vínculo empregatício, de segurança no emprego e no trabalho, de segurança na representação coletiva dos sindicatos, na segurança de renda.

Foucault (2004: 224), ao argumentar que o liberalismo norte-americano é "uma maneira de ser e de pensar", vai além da análise das balizas teóricas da doutrina que eclodiu o neoliberalismo. Mas, ao mesmo tempo, está dizendo que o neoliberalismo produz uma demanda de subjetivação condizente com as suas tecnologias políticas, ou seja, com específicas exigências de maneiras de ser. $\mathrm{Na}$ atualidade, suspeitamos que o modo de ser precário se tornou a demanda universal do sujeito neoliberal.

A máquina do neoliberalismo, nesse caso, é untada por constantes tecnologias políticas de condução dos modos de ser destinados à aceitação inevitável do precariado, mais precisamente, da autoprecarização existencial. Flexibilidade, adaptabilidade, trabalho temporário, terceirização, autoempreendedorismo, disponibilidade onicronológica, dentre outros elementos, são as exigências de respostas subjetivas constantes aos sujeitos do neoliberalismo. Em uma dinâmica social que alucina a energia psíquica por desorientação segmentar social constante, o oportunismo, a depredação do sentimento de pertença e das associações coletivas como meios de resistências a qualquer dominação social passam a pavimentar as condutas que devem ser otimizadas conforme a programação estratégica da atividade dos indivíduos adaptados ao capital-competência, por seu turno, sempre variável às demandas da adaptocracia neoliberal.

Mas, como um vaga-lume, o capital-competência que hoje brilha em sua utilidade sob medida, amanhã poderá se extinguir, pois não há nada que garanta a sua necessidade aos interesses majoritários de uma política econômica regida pelo rentismo. As consequências podem ser percebidas na análise impecável de Standing (2017: 48):

O precariado não é uma classe organizada que busca ativamente seus interesses, em parte porque está em guerra consigo mesmo. Um grupo dentro dele pode responsabilizar outro por sua vulnerabilidade e indignidade. Um trabalhador temporário com baixo salário pode ser induzido a ver o 'parasita de beneficios sociais' como alguém que obtém mais, de forma injusta e às suas custas. As tensões dentro do precariado estão colocando as pessoas umas contra as outras, impedindo-as de reconhecer que a estrutura social e econômica está produzindo seu conjunto comum de vulnerabilidades. Muitos serão atraídos por políticos populistas e mensagens neofascitas.

O que ocorre, contudo, quando o precariado atinge patamares de demandas de subsistência acima das condições da empresa-unidade de conseguir supri-las? Entra em cena a mitigação da pressão pela subsistência via tecnologia política de concessão de 
aniquilamento do gradiente diferencial inadequado à adaptabilidade neoliberal. O neoliberalismo, assim, encontra o racismo de Estado, fazendo dele investimento instrumental a fim de depurar a capacidade adaptativa de seus indivíduos, visando à hipertrofia dos lucros.

Sob tal conjuntura, emerge um novo tipo de racismo, por sua vez útil à própria governamentalidade neoliberal. O que conta não é a raça como elemento associativo de identidades étnicas, culturais ou grupais; o que passa a contar, na modulação desse novo racismo, são todos e quaisquer obstáculos interpostos na realização da maximização dos lucros, de um lado, e na garantia mínima da unidade-empresa individual de sobrevivência, do outro. Tudo o que representa signo de ameaça ou à máquina neoliberal ou ao precário homo oeconomicus deve ser objeto não mais de uma "limpeza étnica", mas de uma limpeza subjetiva. Tal cenário é manejado por um tipo peculiar de tecnologia política de aplicação ao governo dos vivos: o capitalismo dos corpos racializados.

Aqui, portanto, podemos entender as razões pelas quais o Brasil se tornou um laboratório biopolítico de precarização das estratégias educacionais de inclusão e de afirmação das diferenças. O corpo do deficiente, o corpo da singularidade, o corpo da atipia normativo-eficiente, o corpo indigesto ao sistema, o corpo ingovernável, todos assinalam para uma espécie de antecedente criminal ao sistema: de saída, seus corpos são ineficientes como capital humano. Impedir ou dificultar a inclusão de tais corpos na escola é estratégia biopolítica de exclusão da vida, por ajuntamento das tecnologias do biopoder, que tipifica o ineficiente, lançando-o fora de qualquer condição existencial. Afinal de contas, Gary Becker (1993) deixou bem claro em Capital humano - análise teórica e empírica com especial ênfase na educação: sem habilidades e performances adequadas, o indivíduo é o único culpado de sua própria condição, tornando-se mero trabalhador sem habilidade (unskilled), donde, segundo ele, o fato de enorme massa de afrodescentes, imigrantes, pobres, etc. continuarem na pobreza.

\section{Pontos Concludentes}

Atualizando tal perspectiva, poderíamos dizer que o neoliberalismo tem exercido uma política de antropemia dos corpos ingovernáveis, recusando outras potências da vida e para vida, uma vez que a precarização nos ronda como parâmetro existencial dominante. No final de Tristes trópicos, Lévi-Strauss (2016: 414) sensibiliza o antropocentrismo europeu ao dizer algo a ele acerca de seu horror às culturas antropofágicas, invocando o 
que denominou de antropemia (do grego emein - vomitar). Nesse caso, a antropemia diz respeito à normalidade com a qual a cultura ocidental "expulsa para fora de seu corpo social [homens e mulheres], mantendo-os temporária ou definitivamente isolados, sem contato com a humanidade, em estabelecimentos destinados a este fim" - asilos, manicômios, prisões, campos de concentração, periurbanismos, senzalas, fronteiras, subcidadanias, etc. -, no lugar de devorá-los.

É esse vômito que precisamos denunciar e escancarar os seus abusos. Para tanto, no que concerne à educação, a escola precisaria urgentemente se assumir como espaço de socialização empenhada em estimular as condutas e as associações coletivas. Na era do pleno narcisismo individualista neoliberal, precisamos nos afastar das estratégias de atomização social. Para tanto, a escola é convidada a acolher todos os que são vomitados pelo sistema; os que são, tal como o último vômito do bêbedo, colocados na sarjeta, no escuro das esquinas mal faladas e rejeitados nos espaços de convivência. A escola também precisa contrapor-se, questionar, resistir e lutar contra a precarização da existência. $O$ ponto inicial seria partir das microrresistências contra a política de racismo de Estado atual. Assim, somos chamados a considerar o lugar dos corpos ingovernáveis na educação escolar, pois o racismo de Estado está em colisão com o indivíduo insuportável que precisa ser aniquilado, executado, sequestrado, exilado, perseguido, deixado à mingua para morrer ou devolvido à morte, pois ele simplesmente não merece a vida, a partir do momento em que seu capital humano não é digno de sua capacidade adaptativa à precariedade.

Finalmente, temos de lutar pela defesa da escola pública, pois como res publica, a escola reassume o papel estatal do Estado e não mais o seu papel empresarial. Assim, a luta pela educação universal, democrática e com qualidade é, ao mesmo tempo, uma luta contra toda biopolitização da precarização da existência e contra o chamamento excludente da educação.

Com efeito, as lutas presentificadas na educação inclusiva seriam ainda mais marcantes, pois elas colocam em relevo a necessidade da defesa da inclusão da própria diferença humana em um mundo que passou a normopatologizar a exclusão de toda espécie, fato que, por si mesmo, vem justificando o precariado e o aprofundamento da precarização.

\section{Referências}


BRASIL. CONSTITUIÇÃO DA REPÚBLICA FEDERATIVA DO BRASIL DE 1988. http://www.planalto.gov.br/ccivil_03/constituicao/constituicaocompilado.htm (acesso em 16 de novembro de 2016).

BRASIL. LEI DE DIRETRIZES E BASES DA EDUCAÇÃO NACIONAL (LEI N 9304/96). www.planalto.gov.br/ccivil_03/Leis/L9394.htm (acesso em 16 de novembro de 2016).

CÂMARA DOS DEPUTADOS. Projeto de lei no ${ }^{\circ}$. 3.688/2000. https://www.camara.leg.br/proposicoesWeb/fichadetramitacao?idProposicao $=20$ 050

COMBES, Muriel. La vie inséparée - vie et sujet au temps de la biopolitique. Paris: Éditions Dittmar, 2011.

CRAVEIRO, C.B.A.; MEDEIROS, S. (Orgs.). Diretrizes Curriculares Nacionais para a Educação Básica: Diversidade e Inclusão. Brasília: CNE/MEC/SECADI, 2013.

FOUCAULT, Michel. Em defesa da sociedade. São Paulo: Martins Fontes, 2002.

FOUCAULT, Michel. "Omnes et singulatim”: uma crítica da razão política. In: Ditos e Escritos - vol. IV: Estratégia, Poder-Saber. Rio de Janeiro: Forense Universitária, 2003, p. 355-385.

FOUCAULT, Michel. Naissance da la biopolithique. Paris: Gallimard/Seuil, 2004.

FOUCAULT, Michel. História da sexualidade 1: a vontade de saber. Rio de Janeiro, Graal, 2005.

FOUCAULT, Michel. Segurança, Território, População. São Paulo: Martins Fontes, 2008a.

FOUCAULT, Michel. Nascimento da Biopolítica. São Paulo: Martins Fontes, 2008b.

FOUCAULT, Michel. L'origine de l'herméneutique de soi. Paris: Vrin, 2013.

FOUCAULT, Michel. Do governo dos vivos. São Paulo: WMF Martins Fontes, 2014a.

FOUCAULT, Michel. Genealogia da Ética, Subjetividade e Sexualidade. In: Ditos e Escritos IX. Rio de Janeiro: Forense Universitária, 2014b.

FRIEDMAN, Milton. “The Role of Government in Education”. In: SOLO, Robert A. (Org.) Economics and the Public Interest. New Jersey: Trustees of Rutgers College, 1955, p.1-12.

GALLEGO, Esther Solano. O ódio como política. A reinvenção das direitas no Brasil. São Paulo: Boitempo, 2018.

GALLO, Sílvio. “'O pequeno cidadão’: sobre a condução da infância em uma governamentalidade democrática". In: RESENDE, Haroldo. (org.). Michel Foucault - O governo da infância. Belo Horizonte: Autêntica, 2015, p. 329-343.

GALLO, Sílvio. Biopolítica e Subjetividade: resistência?. Educar em Revista, Curitiba, v. 33, n. 66, out./dez. 2017b, p. 77-94.

GALLO, Sílvio. Governamentalidade democrática e ensino de filosofia no Brasil contemporâneo. Cadernos de Pesquisa (Fundação Carlos Chagas), v.42, 2012, p.48 - 64 . 
GALLO, Sílvio. Políticas da diferença e políticas públicas em educação no Brasil. Educação e Filosofia, Uberlândia, v. 31, n. 63, p. 1497-1523, set./dez. 2017a.

HABERMAS, Jurgen. Conhecimento e Interesse. Rio de Janeiro: Zahar, 1982.

HOSANG, Daniel M.; LOWDNS, Joseph E. Producers, parasites, patriotes. Race and the new right-wing politics of precarity. London/Minneapolis: University of Minnesota Press, 2019.

LAZZARATO, Maurizio. Fascismo ou revolução? O neoliberalismo em chave estratégica. São Paulo: N-1, 2019.

LÉVI-STRAUSS, Claude. Tristes Trópicos. São Paulo: Cia das Letras, 2016.

MELAMED, Jodi. The Spirit of Neoliberalism: From racial liberalism to Neoliberal multiculturalismo. Social Text 89, Vol. 24, No. 4, Winter 2006. Disponível em: https://analepsis.files.wordpress.com/2017/01/neolibmulticulti.pdf

PAGNI, Pedro Angelo. A deficiência em sua radicalidade ontológica e suas implicações éticas para as políticas de inclusão escolar. Educação e Filosofia. Uberlândia, v. 31, n. 63, set./dez. 2017, p. 1443-1474.

SENELLART, Michel. As artes de governar. São Paulo: Editora 34, 2006.

STANDING, Guy. O precariado. A nova classe perigosa. Belo Horizonte: Autêntica, 2017

Alexandre Filordi de Carvalho Universidade Federal de São Paulo

E-mail: afilordi@gmail.com

Silvio D. de Oliveira Gallo

Universidade Estadual de Campinas

E-mail: silvio.gallo@gmail.com

\footnotetext{
${ }^{1}$ Expressão latina que significa a todos e a cada um.

${ }^{2}$ Em Conhecimento e Interesse, Jurgen Habermas (1982) definiu três técnicas que, articuladas, configuram a ação humana: técnicas de produção (os sistemas produtivos de trabalho); técnicas de significação (as linguagens); e técnicas de dominação (o exercício do poder sobre outrem). Foucault (2013) se apropria da noção de técnica, muito cara a ele, por implicar numa prática, e acrescenta um quarto tipo, as técnicas de si, através das quais o sujeito age sobre si mesmo, transformando-se.

${ }^{3}$ Está para ser feita uma história da governamentalização do Estado no Brasil; não teríamos condições de fazê-lo aqui, apenas esboçamos algumas ideias gerais para centrar nossa análise nas últimas décadas do Estado republicano brasileiro.

${ }^{4}$ O tema foi explorado por Gallo em diferentes artigos. Ver: GALLO, 2012; GALLO, 2015; GALLO, 2017a; GALLO, 2017b.

${ }^{5}$ Nos artigos de Gallo citados anteriormente, diferentes aspectos desta produção biopolítica são tratados através do operador conceitual governamentalidade democrática.

${ }^{6}$ A este respeito, ver GALLO, 2017a, já citado, além de PAGNI, 2017.
} 